\title{
LA AUCTORITAS SUBVERTIDA: MAGISTER Y DISCIPULUS EN LA EXPOSITIO VIRGILIANAE CONTINENTIAE DE FULGENCIO EL MITÓGRAFO
}

\author{
JULIETA CARDIGNI
}

RESUMEN: La Expositio uirgilianae continentiae de Fulgencio el Mitógrafo -escrita a fines del siglo $\mathrm{V} \mathrm{d}$. C., o a principios del VI- se articula sobre una serie de supuestos que de inmediato nos remiten al imaginario de dos escenarios didáctico-discursivos de la literatura latina tardoantigua. Por un lado, el de la escuela del grammaticus, con la omnipresencia de Virgilio, de la normativa linguíistica, y de la prescripción cultural. También funciona como subtexto el comentario filosófico, más interesado en la interpretación y la exégesis, a partir de las cuales desarrollar doctrinas religiosas o filosóficas. Fulgencio articula su lectura de Virgilio en forma de diálogo. A través de la conversación entre magister y discipulus, la Eneida es explicada de manera alegórica en términos de las etapas de la vida del hombre, a lo cual se suma la sanción cristiana para clausurar el significado. Fulgencio hace que Virgilio, cual grammaticus, le proponga la interpretación alegórica de su poema, para luego completar la lectura con la sanción cristiana, por medio de la cita de las Escrituras. Este diseño narrativo lleva a la redefinición de las figuras de magister y discipulus y a una reformulación de la noción de auctoritas.

El presente trabajo estudia la construcción de las figuras de magister y discipulus en relación con los subtextos de los comentarios tardoantiguos, con el objetivo de detectar las transformaciones operadas, el registro en que estas transformaciones tienen lugar, y la clave de lectura que propone Fulgencio para la obra de Virgilio.

Palabras clave: Antigüedad Tardía - Fulgencio - Virgilio - magister - discipulus.

ABSTRACT: The Expositio uirgilianae continentiae -written by Fulgentius the Mythographer around the end of the $5^{\text {th }}$ century A. D., or at the beginning

\footnotetext{
${ }^{1}$ UBA-UNIPE-CONICET. E-mail: jcardigni@yahoo.es

Fecha de recepción: 30/11/2021; fecha de aceptación: 9/12/2021.

DOI: https://doi.org/10.46553/sty.30.30.2021.p182-199
}

Stylos. 2021; 30 (30); pp. 182-199; ISSN: 0327-8859; E-ISSN: 2683-7900 
of the $6^{\text {th }}$ - is articulated on a series of assumptions that immediately refers us to the imaginary of two didactic discursive scenarios of Late Latin Literature. On one hand, the school of the grammaticus, with the omnipresence of Virgil, and linguistic and cultural normative. On the other hand, philosophical commentary, similar genre, but external to school and more interested in interpretation and exegesis. Fulgentius articulates his work in the form of a dialogue, through which Virgil's work is explained allegorically in terms of the stages of man's life. After that, the Christian sanction is added in order to close the meaning. Fulgentius asks Virgil, as grammaticus, to propose the allegorical interpretation of his poem, and then he completes the reading with the Christian sanction, through the quotation of the Holy Scriptures. This narrative design leads to the redefinition of the categories of magister and discipulus, as to a reformulation of the concept of auctoritas.

The present paper aims to study the construction of the figures of magister and discipulus in relation to the subtexts of late antique commentary, with the purpose of detecting the transformations operated, the register in which these transformations take place, and the reading key proposed by Fulgentius in order to read Virgil's work.

Keywords: Late Antiquity - Fulgentius - Virgil - magister - discipulus.

\section{MAESTROS Y DISCÍPULOS EN EL ENCICLOPEDISMO TARDOANTIGUO}

¿Qué podemos decir sobre la escuela tardoantigua y sus maestros? Para empezar, que la escuela es, durante la Antigüedad Tardía, una institución que se mantiene como en las épocas clásicas, al menos en apariencia, y que constituye uno de los elementos esenciales en la conformación de la identidad cultural: en los siglos que nos ocupan (IV- V- VI) todos los hombres de la aristocracia -fueran estos paganos, o ya cristianos, en época de Fulgencio- recibían la misma educación, basada en los clásicos y fundamentalmente en Vir-

Stylos. 2021; 30 (30); pp. 182-199; ISSN: 0327-8859; E-ISSN: 2683-7900 
gilio. ${ }^{2}$ El culto de la imitatio, una de las bases de la producción literaria de la época, encuentra en la escuela su germen más directo, y así, la educación común a todos los hombres tardoantiguos es uno de los elementos fundamentales en lo que se ha denominado "Poética tardoantigua", "estética tardoantigua", o "tercera sofística". 3

Lo cierto es que en esta línea se llevaba adelante la educación en el Tardoantiguo, con Virgilio como protagonista sobre todo en la escuela del grammaticus, donde los estudiantes aprendían y sistematizaban la lengua, y también una cantidad de elementos de lo que hoy llamaríamos "cultura general". Haciendo honor a la definición de Quintiliano (de la gramática como "recte loquendi scientiam et poetarum enarrationem", Inst. Orat. 1.4-9), el maestro de escuela leía a Virgilio y enseñaba a sus estudiantes valores morales, ya fuera que estuvieran asociados a la lengua, ya fuera que abarcaran elementos de historia, geografía, mitología, y todo aquello que constituyera parte esencial de la identidad del ciudadano romano tardoantiguo.

Por supuesto, esto no debe hacernos creer que la educación era exactamente igual que en la Roma clásica. Las lecturas, las interpretaciones y las instrucciones del gramático estaban en función de la configuración de una nueva identidad, que si bien se pretendía como la tradicional romanitas, ciertamente era una instancia transformada y adaptada a los tiempos que corrían. Por poner ejemplos de dos ámbitos en que los que el gramático instruía, pensemos, por un lado, en la lengua y, por otro, en los mitos. La lengua había cambiado a lo largo de los años, y ciertamente el gramático no podía tomar a Virgilio como modelo a imitar de manera real, dado que además de la variación diacrónica se sumaba el registro poético. Por eso encontramos constantemente comentarios - por ejemplo, en el corpus serviano- que señalan estas diferencias y abogan por la versión contemporánea (In Aen. 1.144): ${ }^{4}$

\footnotetext{
${ }^{2}$ Sobre la escuela del gammaticus cf. KASTER (1988); sobre la educación común de la aristocracia tardoantigua, cf. CAMERON (1977). Sobre Fulgencio y su datación, cf. HAYS (1996).

${ }^{3}$ Sobre el concepto de "Poética tardoantigua" cf. ElSNER- HERÁndEZ LoBATO (2017); sobre la "estética tardoantigua" cf. FONTAINE (1977); sobre la "tercera sofística" cf. QUIROGA (2010), PERNOT (2010).

${ }^{4}$ Sigo el texto de G. Thilo- H. Hagen (1888-1902); la traducción es mía.
}

Stylos. 2021; 30 (30); pp. 182-199; ISSN: 0327-8859; E-ISSN: 2683-7900 
adnixus antiquum est, ut 'conixus', quibus hodie non utimur; dicimus enim 'adnisus' en 'conisus'. Sed multa alia usus contra antiquitatem vindicavit. Ille enim 'parsi' dicebant, nos dicimus 'peperci'. Item nos dicimus 'suscepi', illi dicebant 'succepi', ut 'succepitque ignem fo${\text { liis }{ }^{\prime}}^{5}$

(“'adnixus' es antiguo, como 'conixus', que hoy en día no usamos; en efecto, decimos 'adnisus' y 'conisus'. Y también muchas otras cosas reivindicó el uso frente a la Antigüedad. Por ejemplo, ellos decían 'parsi', nosotros decimos 'peperci'. De la misma manera nosotros decimos 'suscepi', ellos decían 'succepi', como 'y sostuvo el fuego en las hojas'.”)

La enseñanza de la lengua, entonces, implica un delicado equilibrio entre la auctoritas poética de los textos que se leían, y el usus efectivo que se verificaba en, por ejemplo, el siglo V. ${ }^{6}$ Respaldado por la auctoritas que emanaba de su posición institucional -ya que no de su estatus social- el gramático legislaba y ordenaba la lengua

Por otro lado, en la interpretación de los mitos se cuela también la moral tardoantigua, que ve en el evemerismo o racionalismo una estrategia adecuada para transformar esas lejanas historias en ejemplos cotidianos a imitar o evitar. Así, por ejemplo, cuando Servio explica la historia de Júpiter, señala (In Aen. 3.104):

ut autem fingatur Saturnus filios suos comesse, ratio haec est, quia dicitur deus esse aeternitatis et saeculorum. saecula autem annos ex se natos in se revolvunt: unde Graece Koóvos quasi

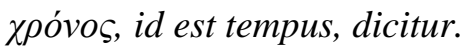

("Pues aunque se cuenta que Saturno se comió a sus hijos, esta es la explicación: es considerado el dios de la eternidad. Así, los años nacidos a partir de

\footnotetext{
${ }^{5}$ La cita que utiliza como ejemplo Servio pertenece a Eneida 1.175.

${ }^{6}$ Este equilibrio que necesita lograr el comentarista está bien descripto por SLUITER (1999) a partir de una serie de tensiones que describe como constitutivas del comentario.
}

Stylos. 2021; 30 (30); pp. 182-199; ISSN: 0327-8859; E-ISSN: 2683-7900 
él, hacia él vuelven: de ahí que en griego se le dice Cronos, como chrónos, o sea, tiempo.")

Como vemos, sin salirse de la descripción de su tarea, el gramático ofrece una educación que es, al mismo tiempo, imitatio y metamorfosis de los moldes clásicos. En su persona se concentra la autoridad, basada en una pretendida "naturalidad" de la norma lingüística y también exegética, ${ }^{7}$ y de él emana la nueva norma, que funcionará como base común identitaria para todos los miembros de la aristocracia imperial tardía.

Por otro lado, algunas veces encontramos la voz del discípulo en los textos gramaticales. En el caso de Servio no ocurre esto, ya que el texto que tenemos fue probablemente una suerte de manual o apuntes de clase destinados más bien a otros maestros. Pero, por ejemplo, al comienzo del Ars minor de Donato, sobre las "partes del discurso", encontramos los siguientes intercambios:

-Partes orationis quot sunt?

-Octo.

-Quae?

-Nomen, pronomen, verbum, adverbium, participium, coniunctio, praepositio, interiectio.

-Nomen quid est?

(“¿Cuántas son las clases de palabras? -Ocho. --¿Cuáles son? -El nombre, el pronombre, el verbo, el adverbio, la conjunción, la interjección. --¿Qué es el nombre?). ${ }^{8}$

Y algo similar ocurre en el De musica Agustín (al comienzo del libro 1):

MAGISTER - Modus, qui pes est?

DISCIPULUS - Pyrrhichius.

M. - Quot temporum est?

${ }^{7}$ Sobre las prácticas del gramático cf. KASTER (1988).

${ }^{8}$ Sigo el texto de KeIL (1868). Las traducciones son mías.

Stylos. 2021; 30 (30); pp. 182-199; ISSN: 0327-8859; E-ISSN: 2683-7900 
D. - Duum.

M. - Bonus, qui pes est?

D. - Idem qui et modus.

M. - Hoc est ergo modus, quod bonus.

D. - Non.

("M(Maestro): - El vocablo modus, ¿qué pie es?

$\mathrm{D}$ (Discípulo): - Un pirriquio.

M.: - ¿De cuántos tiempos consta?

D.: - De dos.

M.: -Bonus, ¿qué pie es?

D.: - El mismo que modus.

M.: - Entonces, modus es lo mismo que bonus.

D.: -No." $)^{9}$

Esta voz aparece como estrategia discursiva destinada a hacer avanzar el discurso, ya que no se observan verdaderos diálogos, sino más bien preguntas disparadoras que requieren la instrucción. Es una voz confirmadora de las enseñanzas del gramático, la mayoría de las veces, estableciendo claras jerarquías a nivel interpersonal. Otro caso interesante puede ser Saturnalia de Macrobio (s. V d.C.), si bien no se trata de un manual escolar, sino más bien un compendio elaborado fuera de la institución, en el que Macrobio busca de alguna manera complementar o corregir cuestiones que no le convencen de la escuela. No olvidemos que la polémica entre gramáticos profesionales y aficionados es de larga data en la cultura romana (¡y griega!). Macrobio mismo nos recuerda (Sat. 1.24.12):

"Nec his Virgilii uerbis copia rerum dissonat, quam plerique omnes litteratores pedibus inlotis praetereunt, tamquam nihil ultra uerborum explanationem liceat nosse grammatico. Ita sibi belli isti homines certos scientiae fines et uelut quaedam pomeria et effata posuerunt.Sed nos, quos crassa Minerva dedecet, non patiamur abstrusa esse adyta sacri poematis, sed archanorum sensuum inuestigato

\footnotetext{
${ }^{9}$ Sigo el texto de la PL de Migne (1844-1864) y las traducciones son mías.
}

Stylos. 2021; 30 (30); pp. 182-199; ISSN: 0327-8859; E-ISSN: 2683-7900 
aditu doctorum cultu celebranda praebeamus reclusa penetralia. "Sed nos, quos crassa Minerva dedecet, non patiamur abstrusa esse adyta sacri poematis, sed archanorum sensuum inuestigato aditu doctorum cultu celebranda praebeamus reclusa penetralia."

("Y no es discordante con estas palabras de Virgilio la abundancia de asuntos que la mayoría de los gramáticos pasan de largo con los pies sucios, como si no le fuera lícito al gramático conocer en absoluto una explicación más allá de las palabras. Así, esos hombres seguros impusieron unos rígidos límites seguros a su ciencia a modo de espacios sagrados. Pero en mi caso yo, a quien una tosca Minerva no desagrada, no debo soportar que se hayan escondido los santuarios del poema sagrado, sino que, investigando el acceso a los conocimientos arcanos, facilitaré que las puertas secretas sean celebradas por el culto de los sabios." $)^{10}$

Claramente, entonces, Macrobio se sitúa en el polo de los aficionados, no solo con Saturnalia -como apreciamos en la cita- sino también con sus Commentarii in Somnium Scipionis, obra que responde al género del comentario filosófico. Este se diferencia del escolar justamente por centrarse en contenidos filosóficos para comentar, y por tener un formato que tiende a ser más monográfico. Asimismo, el comentario filosófico tiene como estrategia principal la lectura alegórica, que busca desplegar sentidos y develar los misterios ocultos en los textos. En el caso de Macrobio, el destinatario y lector ideal es su hijo, pero no aparece representado como voz en el texto, sólo aludido por medio de las dedicatorias, a comienzos de cada libro, respectivamente: "Eustathi fili, uitae mihi dulcedo pariter et gloria" ("Eustacio, hijo mío, gloria y dulzura de mi vida") y "Eustathi luce mihi dilectior fili" ("Eustacio, hijo mío, más amado para mí que la luz.").

Por su parte, Saturnalia pone en escena la situación de enseñanza aprendizaje, en el diálogo en general, pero en particular en los intercambios que el grammaticus Servio -muy diferente del que emerge del corpus serviano- tiene con los invitados cuando, a pedido de uno de ellos, los instruye sobre cuestiones lingüísticas. Desde ya, no es una situación de escuela la que

${ }^{10}$ Sigo la edición de WiLLIS (1970) y las traducciones son mías.

Stylos. 2021; 30 (30); pp. 182-199; ISSN: 0327-8859; E-ISSN: 2683-7900 
estamos leyendo, hay que tener eso en cuenta, sino la situación ficcional del banquete filosófico. Sin embargo, resulta interesante ver a algunos de los invitados escapando un poco a la voz sumisa del discípulo modelo. Estas disrupciones de la armonía del banquete tienen como objetivo crear una suerte de antagonistas en el diálogo, que al mismo tiempo hacen avanzar el discurso. Sin embargo, no puede dejar de notarse cierto desenfado y antipatía en las preguntas e intervenciones de, por ejemplo, Evángelo, que en 1. 24. 2-4 primero declara:

Inter haec Euangelus: Equidem, inquit, miror potuisse tantorum potestatem numinum conprehendi: uerum, quod Mantuanum nostrum ad singula, cum de divinis sermo est, testem citatis, gratiosius est quam ut iudicio fieri putetur. An ego credam, quod ille, cum diceret: Liber et alma Ceres pro sole ac luna, non hoc in alterius poetae imitationem posuit, ita dici audiens, cur tamen diceretur ignorans? Nisi forte, ut Graeci omnia sua in inmensum tollunt, nos quoque etiam poetas nostros uolumus philosophari: cum ipse Tullius, qui non minus professus est philosophandi studium quam loquendi, quotiens aut de natura deorum aut de fato aut de diuinatione disputat, gloriam quam oratione conflavit incondita rerum relatione minuat. $^{11}$

("En medio de esto, Evángelo dijo: 'Ciertamente me asombra que se haya podido abarcar el poder de tantas deidades; ahora bien, que nuestro mantuano, cuando se conversa sobre los asuntos divinos, sea citado en relación con cada una de ellas en calidad de testimonio más bien resulta tendencioso que pueda considerarse justificado. ¿Yo debo creer que él, al decir "Líbero y la nutricia Ceres" en lugar del Sol y la Luna, no pudo haber dicho esto para imitar a potro poeta, al oír que se decía así, ignorando, sin embargo, por qué se decía? Salvo que, por casualidad, al igual que los griegos dicen de todo lo suyo que es lo más grande, nosotros también queramos que nuestros poetas filosofen, cuando el propio Tulio, que no se dedicó menos al estudio de la filosofía que al de la oratoria, cuantas veces disputa sobre la naturaleza de

${ }^{11}$ Sigo el texto de KASTER (2011) y la traducción es mía.

Stylos. 2021; 30 (30); pp. 182-199; ISSN: 0327-8859; E-ISSN: 2683-7900 
los dioses o del destino, o sobre la adivinación, mengua su gloria -que resplandeció en la oratoria- al relacionar sin arte sus argumentos.")

Ciertamente esta es la excusa para que Símaco se embarque en una elegante e implacable defensa de Virgilio y su obra, censurando indirectamente las opiniones de Evángelo. ${ }^{12}$ Como sea, lo que la lectura de Saturnalia, en conjunto con los tratados gramaticales, nos demuestra, es que en principio el discípulo debía tener esta actitud sumisa e ingenuamente curiosa, que no desafiara al maestro sino que colaborara con él en la instrucción, y que en todo caso con sus preguntas hiciera avanzar el proceso de enseñanzaaprendizaje. De esta manera, el discípulo colabora también con la construcción de la auctoritas del maestro, ya que se ubica jerárquicamente en el lugar inferior respecto del conocimiento, requisito fundamental para que se produzca la instrucción.

\section{LA EXPOSITIO Y LA SUBVERSIÓN DE LA ESCUELA}

Todo cambia, por supuesto, cuando nos encontramos con el texto de Fulgencio. Para empezar, la Expositio uirgilianae continentiae de Fulgencio el Mitógrafo - escrita a fines del siglo V d. C., o quizá a principios del VI- se articula sobre una serie de supuestos que de inmediato nos remiten al imaginario de los dos escenarios didáctico-discursivos de la literatura latina tardoantigua que hemos comentado. Por un lado, el de la escuela del grammaticus, con la omnipresencia de Virgilio, de la normativa lingüística, y de la prescripción cultural. Por otro lado, también funciona como subtexto el comentario filosófico, género similar pero ajeno a la escuela, más interesado en la interpretación y la exégesis, a partir de las cuales desarrollar doctrinas religiosas o filosóficas. Además de Macrobio, que escribió sus Commentarii in Somnium Scipionis, en el siglo V d. C., es también representante de este género Calcidio, con su traducción y comentario del Timeo platónico a fines del siglo IV. Asimismo, Saturnalia, por su configuración discursiva y la construcción del

\footnotetext{
12 También ha sido motivo de que la crítica considere que hay una crítica velada al cristianismo cifrada en el nombre de este personaje, el más antipático del diálogo.
}

Stylos. 2021; 30 (30); pp. 182-199; ISSN: 0327-8859; E-ISSN: 2683-7900 
fenómeno de enseñanza- aprendizaje, constituye un subtexto valioso para la interpretación de la Expositio.

Fulgencio abreva de ambos tipos discursivos -comentario gramatical, comentario filosófico- y articula su lectura de Virgilio en forma de diálogo, como ocurre en el banquete. A través de la conversación entre magister y discipulus, la Eneida es explicada de manera alegórica en términos de las etapas de la vida del hombre, a lo cual se suma la sanción cristiana para clausurar el significado. En una época en que se buscaba construir la paideía cristiana por medio de la transformación de las matrices retóricas del paganismo, la obra de Fulgencio es al mismo tiempo el primer intento sistemático de cristianización de Virgilio, y una puesta en práctica de la lectura alegórica, la estrategia más utilizada para tal fin.

Como si esto no fuera ya lo suficientemente interesante para tentarnos a la lectura, el encargado de explicar la Eneida es el propio Virgilio, invocado por un Fulgencio-discípulo que busca releer la obra virgiliana en clave cristiana. Quizá para no hacerlo directamente, Fulgencio prefiere que Virgilio, cual grammaticus, le proponga la interpretación alegórica de su poema, para luego completar la lectura con la sanción cristiana, por medio de la cita de las Escrituras. Esta doble mediación sobre el texto nos habla de un claro proyecto por parte del autor: no leer en forma directa la Eneida, sino su interpretación alegórica; y no ser él mismo quien la lee, sino crear una situación didáctica ficcional para poner en escena la lectura, a cargo del propio poeta.

Sin duda, este diseño narrativo lleva a la redefinición de las figuras de magister y discipulus desde el punto de vista discursivo, y también a una reformulación de la relación entre ambos. La noción de auctoritas, que establece la jerarquía desigual entre el maestro y su discípulo, se ve aquí problematizada por el entorno ficcional: el personaje principal es al mismo tiempo discipulus y auctor, aprendiz y maestro.

Veamos entonces cómo se construyen las figuras de magister y discipulus en relación con los subtextos de los comentarios tardoantiguos, con el objetivo de detectar las transformaciones operadas, el registro en que estas transformaciones tienen lugar, y la clave de lectura que propone Fulgencio para la obra de Virgilio.

Stylos. 2021; 30 (30); pp. 182-199; ISSN: 0327-8859; E-ISSN: 2683-7900 
En principio, es el propio Fulgencio, que como autor- narrador de la Expositio, invoca a Virgilio para que le explique su obra, y se constituye así como discípulo, y a Virgilio como magister y grammaticus, cuando le solicita, en $84-85:{ }^{13}$

nam non illa in tuis operibus quaerimus in quibus aut Pitagoras modulos aut Eraclitus ignes aut Plato ideas aut Ermes astra aut Crisippus numeros aut endelecias Arisoteles inuersat, (...), sed tantum illa quaerimus leuia, quae mensualibus stipendiis grammatici distrahunt puerilibus auscultatibus.

("No busco en tus obras aquello que busca Pitágoras en los módulos, Heráclito en el fuego o Platón en las ideas, Hermes los astros, Crisipo los números o Aristóteles las entelequias. (...) Sólo busco aquellos argumentos ligeros que despiezan los maestros de escuela a cambio de un estipendio mensual y que escuchan los alumnos.")

La analogía con la escuela del gramático es explícita, y también la actitud de Fulgencio hacia ella: los grammatici distrahunt, "destraen", "despiezan" los contenidos. Fulgencio rechaza explícitamente un tipo de comentario más profundo, que busca lo oculto -como podía ser el del comentario filosófico- y busca los saberes y las lecturas que el gramático hace en la escuela, casi como un eco de la crítica macrobiana. También al principio de su obra ha rechazado la posibilidad de hablar sobre Geórgicas y Bucólicas, considerando que ocultan secretos "peligrosos" (82): "Virgilianae continentiae secreta phisica tetigi uitans illa quae plus periculi possent praerogare quam laudis. Uae inquam nobis, aput quos et nosse aliquid periculum est et habere." ("He aceptado hablar de los secretos del mundo natural que se hallan contenidos en la obra de Virgilio, evitando aquellos que podrían comportar mayor peligro que alabanza.").

Incluso cuando Virgilio intenta elevar un poco el contenido de lo que comentará, Fulgencio lo frena en seco diciendo (85): "Serua ista quaeso tuis Romanis, quibus haec nosse laudabile competit et inpune succedit; nobis ue-

${ }^{13}$ Sigo el texto de Helm (1898) y la traducción es mía.

Stylos. 2021; 30 (30); pp. 182-199; ISSN: 0327-8859; E-ISSN: 2683-7900 
ro erit maximum, si uel extremas tuas praestringere cortingerit fimbrias." ('Guarda, te ruego, esas alabanzas para tus romanos, para los cuales este género de conocimiento [¿la Filosofía?] es título de alabanza y su obtención los mantiene impunes. Yo habré llegado a lo máximo si alcanzo apenas a rozar el borde de tu vestido'.) Para empezar, entonces, tenemos un discípulo que pauta los contenidos que su maestro debe transmitirle, que lo corrige cuando se descarrila, y que no acepta cambios de planes.

A su vez, sabemos que Fulgencio fue a la escuela, dado que Virgilio, para estar seguro de que conoce el argumento de Eneida, lo interroga al respecto, y él le responde (89-90):

"Sed ut sciam me non arcaicis ${ }^{14}$ expromtare fabulam auribus, primi nostri libri continentiam narra; tune demum haec tibi, si uisum fuerit, reserabimus". Cui ego: Si me scolarum praeteritarum non fallit memoria, primum luno Eolum petit, quo naufragium Troianis inportet. Dehinc cum septem nauibus euadit. Libico in litore accipitur. Matrem uidit nec agnoscit. Nube caua cum Acate contegitur. Dehinc picturis animum aduocat. Posthaec cena acceptus citharae sonó mulcetur. Habes breuiter decursam primi libri continentiam. Quid de his senseris, audire desidero.

("Pero para estar seguro de que no cuento un cuento para oídos no preparados, ofréceme una descripción del contenido de estos libros nuestros. Sólo después, si me pareciese oportuno, te abriré la puerta a su sentido. Y yo a él: «Si no me falla la memoria de aquello que aprendí en la escuela primero Juno rogó a Eolo que condujese al naufragio, a los troyanos. Después Eneas consiguió salvarse con siete naves. Las atracó en el litoral de Libia. Allí vio a su madre, pero no la reconoció. Se ocultó junto a Acate dentro de una espesa nube; consoló entonces su alma admirando unas pinturas y después, invitado a cenar, fue confortado por el sonido de la cítara. He aquí brevemente narrado el contenido del libro primero. Deseo ahora escuchar lo que piensas de esto»")

14 “Antiguos", "no informados"; incluso "paganos" en la propuesta de AGOZZINO (1972).

Stylos. 2021; 30 (30); pp. 182-199; ISSN: 0327-8859; E-ISSN: 2683-7900 
Aquí está claro, entonces, que lo que Fulgencio busca es una interpretación de los contenidos que vio en la escuela, porque de alguna manera no le parece suficiente. Fulgencio recuerda los hechos (y sin duda podemos vislumbrar aquí una crítica a la escuela del gramático) pero quiere una interpretación. Y eso es lo que hará Virgilio en la Expositio, revelando su estrategia de composición de la Eneida: (89): "Ergo sub figuralitatem historiae plenum hominis monstrauimus statum, it sit prima natura, secunda doctrina, tertia felicitas." ("A través de una historia simbólica/ alegoría he mostrado el estado entero del hombre, indicando en primer lugar lo que se refiere a la naturaleza, en segundo lugar, a la doctrina y en tercera posición a la felicidad.").

A las interpretaciones del poeta, Fulgencio suma la sanción moral de las Escrituras; por ejemplo, al explicar el episodio de Miseno y Tritón en clave etimológica (95):

Vides enim quam fixa proprietas; uanae enim laudis tumor uentosa uoce turgescit, quem quidem Tritón interimit quasi tetrimmenon quod nos Latine contritum dicimus; omnis ergo contritio omnem uanam laudem extinguit. Ideo et Tritona dicta est dea sapientiae; onrnis enim contritio sapientem facit'. Cui ego: Certior ego hanc tuam comprobó doctor sententiam; nam et nostra salutaris diuinaque praeceptio cor contritum et humiliatum Deum non dispicere praedicat.

('Observa cómo ha sido fijada esta propiedad: el orgullo de la vanagloria se hincha de palabras llenas de viento ${ }^{15}$ [esta es la explicación de la etimología de "Miseno"] y es destruido por Tritón, que equivale a tetrimménon, esto es, en latín, 'contrito'. Toda forma de contrición extingue toda forma de vanagloria. Así, se llama Tritona a la diosa de la sabiduría, porque cada acto de contrición hace al hombre sabio'. Y yo le dije: 'Concuerdo, maestro, con tu opinión, pues nuestra doctrina predica que Dios no desprecia un corazón contrito y humillado. ${ }^{16}$ ).

\footnotetext{
${ }^{15}$ Virgilio, Eneida 11.390.

${ }^{16}$ Cf. Sal 50 19: «cor contritum et humiliatum. Deus, non despides».
}

Stylos. 2021; 30 (30); pp. 182-199; ISSN: 0327-8859; E-ISSN: 2683-7900 
Esta es una de las marcas más fuertes de subversión: el discípulo le enseña al maestro, y posee -a pesar de las jerarquías que se establecen formalmente al principio- un saber que Virgilio ignora y que es, por supuesto, el del cristianismo.

Por supuesto, no tardan en surgir los malentendidos. Virgilio no parece un maestro fácil de dominar, y Fulgencio insiste en encarrilarlo, pero las cosas se salen de control. Virgilio osa hablar del retorno de las almas, y Fulgencio le echa en cara su error, aludiendo también a su acierto en la Égloga IV (que ya en esa época se leía en clave cristiana como la llegada de Cristo). Dice un enojado Fulgencio (101-102):

"Ad haec ego: O uatum Latialis autenta, itane tuum clarissimum ingenium tam stultae defensionis fuscare debuisti caligine? Tune ille qui dudum in bucolicis mystice persecutus dixeras: 'lam redit et uirgo, redeunt Saturnia regna; iam noua progenies caelo promittitur alto'. nunc uero dormitanti ingenio Academicum quippiam stertens ais: 'Sublimes animas iterumque ad tarda reuerti corpora'. Numquidnam oportuerat te inter tanta dulcia poma mora etiam ponere tuaeque luculentae sapientiae funalia caligare?"

('Oh el principal de los poetas latinos, ¿tuviste que ofuscar tu clarísimo ingenio con la oscuridad de una absurda defensa? Tú que recientemente en las Bucólicas dijiste persiguiendo el sentido oculto: 'ya vuelve la Virgen, retornan los reinos de Saturno, una nueva progenie viene prometida de lo alto de los cielos'. Ahora das prueba de un ingenio que se duerme a ratos y a la manera del que ronca haces una afirmación que es propia de la Academia [platónica]: (...) ¿Era necesario que entre tantas cosas dulces pusieras también frutos agrestes, empañando la luminaria de tu magnífica sabiduría?")

Pero Virgilio, lejos de ser sumiso ante los embates, a menudo responde con sarcasmo, casi tomándole el pelo a su discípulo (102): Ad haec ille subridens: 'Si, inquit, inter tantas Stoicas ueritates aliquid etiam Epicureum non desipissem, paganus non essem; "No sería pagano si entre tanta verdad estoica no hubiese espolvoreado una pizca de locura epicúrea").

Stylos. 2021; 30 (30); pp. 182-199; ISSN: 0327-8859; E-ISSN: 2683-7900 
En otras ocasiones, el poeta intenta "despegarse" de las interpretaciones fulgencianas (86):

Ad haec ego: Si me tuae orationis adserta non fallunt, uates clarissime, ideo etiam diuina lex nostrum mundi redemptorem Christum uirtutem et sapientiam cecinit, quod perfectum hominis diuinitas adsumpsisse uideretur statum. Ad haec ille: 'Videris ipse quid te uera maiestas docuerit; nobis interim quid uisum sit edicamus.

(A esto respondí yo [Fulgencio]: «Si no he entendido mal los asertos de tu discurso, oh ilustre poeta, también has cantado la ley divina, virtud y sabiduría de Cristo, nuestro redentor en el mundo, queriendo con ello mostrar que la divinidad ha asumido el perfecto estado de hombre». Y él dijo a mis palabras: «Verás tú mismo aquello que la majestad divina te ha revelado; yo entretanto te declararé mi visión").

Y ya un poco más tarde Virgilio pierde la compostura ante los reclamos de su alumno y declara (102): "Neque enim hoc pacto in tuis libris conductus narrator accessi, ut id quod sentire me oportuerat, disputarem et non ea potius quae senseram lucidarem. Audi ergo quae restant."("Pero no he acordado acceder a tus libros como un intérprete cualquiera para discutir contigo aquello que habría debido pensar, sino más bien para elucidar cuál era mi pensamiento. Escucha, pues, el resto.")

\section{SUBVERSIÓN Y PARODIA}

De acuerdo con nuestro análisis entonces, podemos detectar una subversión de las figuras de magister y discipulus en varios niveles, que repercuten en la auctoritas:

1. En primer lugar, respecto del nivel de conocimiento. Si bien la situación didáctica requiere de una asimetría en este aspecto, vemos que lo que se pregona desde el principio no se sostiene de manera inmutable a lo largo del texto. Virgilio explica su obra, pero Fulgencio también, y lo hace sobre la interpretación virgiliana, y no siempre

Stylos. 2021; 30 (30); pp. 182-199; ISSN: 0327-8859; E-ISSN: 2683-7900 
con acuerdo de nuestro poeta grammaticus. Fulgencio posee un saber que Virgilio no, y lo que busca es apropiarse de la auctoritas del poeta para imponer su interpretación.

2. Asimismo, lejos de mantenerse la jerarquía entre maestro y alumno, manifestada en una voz sumisa y complaciente de este último en función de la auctoritas del primero, el trato de Fulgencio hacia su maestro evidencia que este respeto -que veíamos en los casos paradigmáticos de los comentarios escolares, y de Saturnalia de Macrobio- no es tal. Tampoco lo verificamos en el trato de Virgilio hacia su discípulo: si bien su hosquedad no se riñe con la seriedad de la figura del gramático, sus juegos y sarcasmos sí parecen alejarlo de la figura del educador.

3. Finalmente, hay una subversión más, que nos habla del carácter probablemente paródico de la obra de Fulgencio. Virgilio, el poeta más prestigioso y respetado de la tradición, elevado al estatus de vate y sabio inspirado, ${ }^{17}$ está aquí reducido al muy inferior estatus de maestro de escuela que, como sabemos, no goza del mismo prestigio social que un poeta de la aristocracia. No contento con esto, Fulgencio se atreve a cuestionar a esta tan grande figura venida a menos, estableciendo una distancia entre Virgilio, que queda anclado al paganismo de la Roma clásica, y él mismo, ya iluminado por la "chispa" cristiana.

Ya sea que Fulgencio esté buscando advertirnos sobre la superioridad del cristianismo -ampliamente instalado ya en los siglos V y VI-, ya sea que la esté poniendo en cuestión, lo cierto es que ni el maestro ni el discípulo de la Expositio responden a la imagen tradicional que los textos didácticos nos muestran. Hay aquí más bien de una lucha de poderes, que quizá podría quedar desierta, ya que a pesar de que Fulgencio tiene a su cargo la sanción final de las Escrituras, las ironías virgilianas le quitan legitimidad y poder de clausura. Pero al cuestionar la auctoritas por medio de la subversión de roles, se

${ }^{17}$ Sobre la figura de Virgilio en el Tardoantiguo cf. Sток $(2012,1994)$.

Stylos. 2021; 30 (30); pp. 182-199; ISSN: 0327-8859; E-ISSN: 2683-7900 
altera el universo del texto didáctico y podemos llegar a dudar de que el texto cumpla, realmente, una función instruccional. ${ }^{18}$

\section{REFERENCIAS BIBLIOGRÁFICAS}

\section{EDICIONES}

AgOZZINO, T. Y F ZANLUCCHI, Expositio Virgilianae continentiae, Padua: Universita degli Studi di Padova. Accademia Patavina di Scienze, Lettere ed Arti. Istituto di Filología Latina [Collana Accademica, 4], 1972.

HeLm, R. Fabii Planciadis Fulgentii V.C. Opera, Leipzig: Teubner, 1898 (reimpr. 1970).

KASTER, R. Macrobii Ambrosii Theodosii Saturnalia, Oxford-New York, Oxford University Press, 2011.

KeIL, H. Grammatici Latini, ex recensione Henrici Keilii, Donato, Ars Grammaticae, vol. IV, Leipzig, Teubner, 1868.

Migne, J. P. Patrología Latina, París, 1844-1864.

THILO, G.- H. Hagen (eds.). Servius. Vergilii carmina commentarii, Leipzig: Teubner, 1881-1902.

WILLIS, J. Ambrosius Theodosius Macrobius. Lepizig : Teubner, 1970.

BIBLIOGRAFÍA CITADA

CAMERON, A. "Paganism and literature in late fourth century Rome", Entretiens sur l' antiquité classique, 1977 tome XXIII 1-40.

ElSNER, J. - J. Hernández Lobato (eds.). The poetics of late Latin literature. Oxford: Oxford University Press, 2017.

FONTAINE, J. "Unité et diversité du mélange des genres et des tons chez quelques écrivains latins du la fin du IV siècle: Ausone, Ambroise,

\footnotetext{
${ }^{18}$ En esta línea se sitúan las lecturas -que comparto y profundizo- de la Expositio como obra paródica construida sobre las matrices de la sátira menipea (cf. RELIHAN, 1993).

Stylos. 2021; 30 (30); pp. 182-199; ISSN: 0327-8859; E-ISSN: 2683-7900
} 
Ammien", Entretiens sur l'antiquité classique, 1977 tome XXIII: 425- 482.

HAYS, G. "Fulgentius the Mythographer" (Diss. Cornell, 1996).

KASTER, R. Guardians of language: The grammarian and Society in Late Antiquity, Los Angeles: University of California Press, 1988.

PERnOT, L. "La Seconde Sophistique et l'Antiquité Tardive", Classica 2006 19:1, 30- 44

QUIROGA, A. "La tercera sofística en el marco teórico de la historiografía sobre la Antigüedad Tardía y el postmodernismo", Talia Dixit 2010 75- 90.

ReliHan, J. Ancient Menippean Satire, Baltimore: Johns Hopkins University Press, 1993.

SLUITER, I. "Commentaries and the didactic tradition", Glenn W. Most (ed.), Commentaries - Kommentare (Aporemata Bd 4), Göttingen, 1999 173-205.

StoK, F. "Commenting on Virgil, from Aelius Donatus to Servius", Dead Sea Discoveries 2012 19, 464-484.

STOK, F."Virgil Between the Middle Ages and the Renaissance", IJCT, 1994 Vol. 1, No. 2 15-22.

Stylos. 2021; 30 (30); pp. 182-199; ISSN: 0327-8859; E-ISSN: 2683-7900 